\title{
SITUAÇÃO PÓS-ADOÇÃO DOS ANIMAIS ADOTADOS JUNTO A UMA ONG DE PROTEÇÃO ANIMAL NO ESTADO DO RIO DE JANEIRO
}

\author{
THE CURRENT SITUATION OF PETS ADOPTED FROM AN ANIMAL \\ PROTECTION NGO IN THE STATE OF RIO DE JANEIRO
}

\author{
Flavio Fernando Batista Moutinho ${ }^{1 *}$ ORCID - http://orcid.org/0000-0003-2172-8132 \\ Cathia Maria Barrientos Serra ${ }^{1}$ ORCID - http://orcid.org/0000-0002-6748-544X \\ Luiza Carneiro Mareti Valente1 ORCID - http://orcid.org/0000-0001-8131-632X \\ ${ }^{1}$ Universidade Federal Fluminense, Niterói, RJ, Brasil. \\ *Autor para correspondência - flaviomoutinho@id.uff.br
}

\begin{abstract}
Resumo
Este trabalho objetivou analisar a situação dos animais adotados junto a uma ONG fluminense. Foi selecionada uma amostra de conveniência de 50 animais e os adotantes responderam a questionário cujos dados obtidos foram analisados com técnicas de estatística descritiva. De modo geral os adotantes eram casados, sexo feminino, idade variável, nível superior, renda alta, não se guiaram pela raça dos animais e adotaram principalmente mais jovens. As adoções não se deram em função da interação dos animais com idosos e crianças, os adotantes já dispunham de outro animal, os adotados passaram a residir em imóveis residenciais e o principal motivo para a adoção foi a pena. Princípios de guarda responsável eram seguidos, com alta proporção de animais castrados, predomínio de alimentação com ração, boa cobertura vacinal e desverminação periódica. Como pontos negativos temos o predomínio de animais com acesso livre às ruas, deficiência no acompanhamento veterinário e ausência de dispositivo de identificação. Houve grande vínculo dos adotantes com os animais, com alto índice de permanência, pouca dificuldade na lida e alto grau de satisfação. Esse quadro demonstra que a estratégia da adoção foi eficiente e pode trazer bons resultados no controle da densidade populacional de animais, especialmente se aliada a outras estratégias.
\end{abstract}

Palavras-chave: animal não domiciliado, adoção, controle populacional.

\begin{abstract}
This essay aims at analyzing the situation of pets after adoption from an NGO in the State of Rio de Janeiro. A sample of 50 pets was selected, and adopters answered a questionnaire whose data was analyzed by using descriptive statistical techniques. In general, adopters were comprised of married women of different ages, with university degree and high income. They were not lead by the pets' breed and adopted particularly the youngest ones. Adoptions did not take place aiming an interaction between pets and the elderly or children. Adopters already had another pet, and the adopted pets started to live at residential properties. We realized that compassion was the key reason for adoption. Responsible guardianship principles were followed and a high percentage of pets had been neutered. They were feed predominantly with pet food. Good vaccination and frequent deworming practices were in place. As prevailing negative aspects we noticed that animals had free access to the streets, did not receive adequate veterinary care and were not wearing identification tags. Adopters were very attached to their pets. There was a high rate of stay, little difficulty in dealing with the pets and high
\end{abstract}


satisfaction level. This scenario shows us that the adoption strategy has been effective and may bring good results to the control of animal population density, especially if combined with other strategies. Keywords: stray animal, adoption, population control.

Recebido em: 19 de outubro de 2016

Aceito em: 23 de outubro de 2018

\section{Introdução}

A relação de proximidade dos humanos com os cães data do Neolítico e, atualmente, a sociedade vem passando por mudanças drásticas em sua conformação, fazendo com que haja redução do tamanho das famílias e, consequentemente, o aumento da aquisição de cães e gatos em busca de afetividade ${ }^{(1)}$. Ao mesmo tempo, a maioria dos municípios brasileiros vêm enfrentando problemas relacionados à

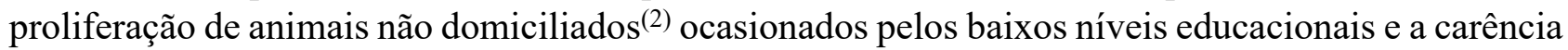
de saneamento.

$\mathrm{Na}$ atualidade, o controle populacional se faz necessário por questões relacionadas à saúde coletiva, ao bem-estar animal e à ordem urbana. A grande quantidade de cães soltos nas ruas pode provocar acidentes de trânsito, destruição dos patrimônios público e privado, maus-tratos contra estes animais, doenças transmissíveis e agressões a $\operatorname{pessoas}^{(3)}$.

A utilização da eutanásia como estratégia de controle populacional de cães e gatos é proibida no Estado do Rio de Janeiro, sendo previstos os programas de esterilização permanentes ${ }^{(4)}$. Diversos municípios brasileiros já adotaram a esterilização como estratégia de controle, em estados como São Paulo $^{(5)}$, Rio de Janeiro ${ }^{(5,6)}$ e Minas Gerais ${ }^{(7)}$.

A adoção de animais abandonados também é uma estratégia de controle populacional, mas muitas vezes a adoção alcança um quantitativo muito aquém da necessidade real, como em Ibiúna-SP, em que num período de oito meses somente $10,2 \%$ dos animais postos para adoção pelo centro de controle de zoonoses foram $\operatorname{adotados}^{(8)}$.

As Organizações Não Governamentais (ONG) de proteção animal têm grande destaque ao pressionarem o governo e desenvolverem ações como a manutenção de abrigos de animais e campanhas de adoção de animais abandonados ${ }^{(9)}$. Pesquisa realizada por Moutinho et al. ${ }^{(10)}$ demonstrou que boa parte dos gestores de serviços municipais de controle de zoonoses do Estado do Rio de Janeiro afirmavam que as ONG eram importantes para o controle populacional dos animais. Historicamente, nos municípios que têm ações de controle populacional, as ONG são importantes, atuando isoladamente ou em parceira com o Poder Público ${ }^{(11,12,13)}$.

No Estado do Rio de Janeiro, a Lei $n^{\circ} 4.808 / 2006$ define responsabilidades aos proprietários destes animais que envolvem questões de saúde e bem-estar ${ }^{4}$. Mas diversos estudos vêm demonstrando que os proprietários de animais de companhia não desenvolvem a guarda responsável de seus $\operatorname{animais}^{(14,15,16)}$.

Garcia et al. ${ }^{(17)}$ consideram o destino dos animais não domiciliados um ponto de estrangulamento do controle populacional e destacam ser fundamental a educação dos novos proprietários de animais. A Organização Mundial de Saúde Animal (OIE) recomenda a adoção de animais com fomento da guarda responsável por parte dos adotantes, e a adoção de animais castrados ${ }^{(18)}$. Diversos estudos já vêm demonstrando o sucesso da adoção de animais domésticos ${ }^{(19,20)}$. Mais importante do que conhecer o quantitativo de animais adotados anualmente é conhecer a realidade desses animais 
adotados após o processo de adoção, prospectivamente. O presente trabalho objetivou fazer uma análise pós-adoção da situação dos animais adotados junto a uma organização não governamental de proteção animal para determinar se o processo de adoção tem sido eficiente, a médio e longo prazos e se são seguidos pelos adotantes os princípios de guarda responsável.

\section{Material e Métodos}

A pesquisa foi realizada com apoio de uma Organização Não Governamental (ONG) de proteção animal, atuante e localizada no município de Cachoeiras de Macacu-RJ. A partir da relação de adotantes de animais do período 2011 a 2015, fornecida pela ONG, foi levantado o quantitativo de caninos e felinos adotados, que foi de 171 animais. Destes foi selecionada uma amostra não probabilística por conveniência totalizando 50 animais, o que equivale a $29 \%$ do total de animais adotados.

Após a seleção, os adotantes foram contatados e responderam a um questionário estruturado, previamente testado, abordando os seguintes temas: perfil do animal adotado, perfil da família adotante, situação atual dos animais adotados, adoção de práticas de guarda responsável pelo adotante, grau de satisfação com o animal adotado e motivação que levou à adoção do animal. Antes da aplicação do questionário os respondentes assinaram o Termo de Consentimento Livre e Esclarecido.

Os dados obtidos nestes questionários foram codificados, tabulados em planilhas do software Excel ${ }^{\circledR}$ e analisados com técnicas de estatística descritiva.

A pesquisa foi devidamente aprovada pelo Comitê de Ética na Pesquisa do Hospital Universitário Antônio Pedro (UFF), conforme parecer $n^{\circ} 1.210 .160$.

\section{Resultados e Discussão}

$\mathrm{Na}$ amostra selecionada havia 31 felinos e 19 caninos. No caso dos felinos houve leve predomínio de machos $(54,8 \%)$ e no caso dos caninos houve um forte predomínio de fêmeas adotadas (79\%). Apesar de diversos estudos apontarem para uma maior presença de machos nos lares brasileiros ${ }^{(21,8,22,23,24)}$, tal resultado na presente pesquisa pode ser somente um reflexo do gênero dos animais disponibilizados para adoção.

Dos caninos adotados, $47,4 \%$ eram de porte grande (a partir de $50 \mathrm{~cm} /$ a partir de $25 \mathrm{~kg}$ ), enquanto $26,3 \%$ eram de porte médio (de 36 até $49 \mathrm{~cm} /$ entre 15 a $25 \mathrm{~kg}$ exclusive) e $26,3 \%$ de porte pequeno (até $35 \mathrm{~cm} /$ até $15 \mathrm{~kg}$ exclusive). Esses dados diferem dos obtidos por Posage et al. ${ }^{(25)}$, que detectaram que cães de pequeno porte foram mais propensos à adoção em abrigo nos EUA, enquanto estudo conduzido por Paploski et al. ${ }^{(26)}$ mostrou que o porte não foi característica decisiva para a adoção, em Botucatu-SP. Cabe ressaltar mais uma vez que os resultados obtidos podem ser consequência dos animais disponíveis para adoção na $\mathrm{ONG}$ no período estudado e não somente resultado da preferência dos adotantes.

Dos animais adotados, a grande maioria, tanto no caso dos caninos quanto no de felinos, era de filhotes e jovens com menos de um ano de idade e o menor percentual envolveu os animais idosos, 
acima de cinco anos (Figura 1). Esses dados diferem daqueles encontrados em pesquisa conduzida por Weiss et al. ${ }^{(23)}$ nos EUA, cujos adotantes demonstraram preferência por adoção de animais idosos nos abrigos.

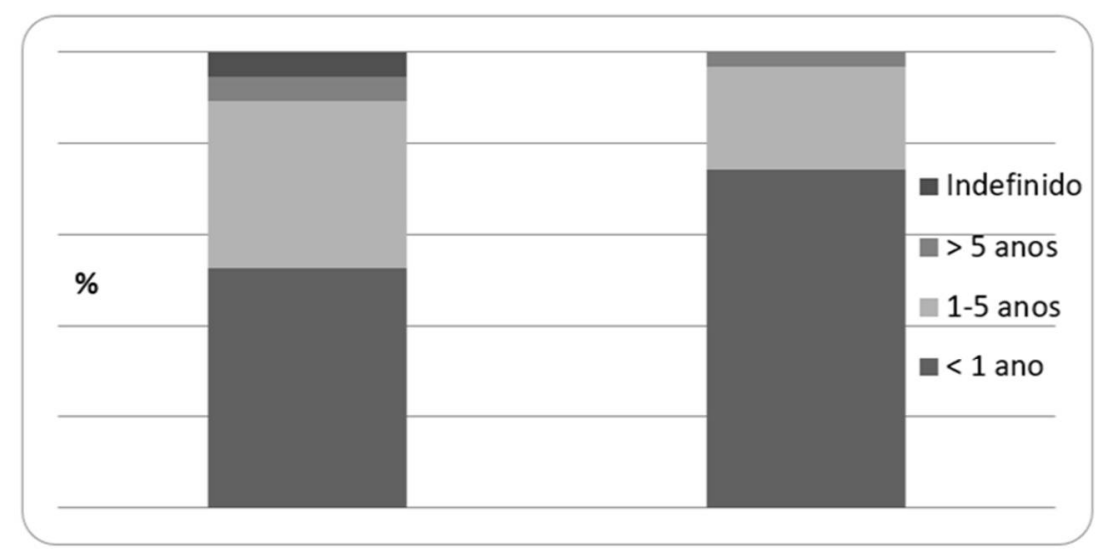

Figura 1. Idade dos animais (caninos e felinos) adotados no período 2011-2015. Cachoeiras de Macacu-RJ.

Apenas dois felinos $(6,4 \%)$ e três caninos $(15,8 \%)$ eram portadores de necessidades especiais. Ainda que não tenham sido encontrados artigos que comprovem isso, acredita-se que animais portadores de necessidades especiais, tenham mais dificuldade para serem adotados.

Do total de animais adotados analisados, $84 \%$ eram castrados, sendo $79 \%$ dos caninos e $87,1 \%$ dos felinos, com a castração ocorrendo logo após o processo de adoção na maior parte em ambas as espécies. Somente $28 \%$ já foram adotados castrados (31,6\% dos caninos e $25,8 \%$ dos felinos). Ao contrário do encontrado no presente estudo, diversas pesquisas vêm mostrando pequena proporção de animais domésticos castrados ${ }^{(15,27,28,29,30)}$. Apesar disso, e concordando com os resultados encontrados, diversos estudos vêm demonstrando uma maior preocupação dos proprietários de gatos em relação à castração de seus animais ${ }^{(31,15,20)}$. A esterilização dos animais é uma das principais estratégias para evitar o abandono e consequente superpopulação de animais não domiciliados. Em não havendo importação de animais de outras áreas, a esterilização contínua permitiria, a longo prazo, a estabilidade e posterior redução da densidade populacional ${ }^{(32)}$. De acordo com Patronek et al. ${ }^{(31)} \mathrm{o}$ principal fator para a não castração dos animais era o custo da cirurgia, daí a importância dos projetos de castração gratuita ou subsidiada.

Houve predomínio de casados como adotantes $(62,4 \%)$. No caso dos caninos estes representaram $70 \%$, enquanto que felinos foram 50\%. O maior percentual de adotantes foi de indivíduos do sexo feminino (75\%), com 70\% no caso de caninos e $83,3 \%$ no caso dos felinos (Tabela 1). Esses resultados estão de acordo com os encontrados com Paploski et al. ${ }^{(26)}$ no qual $55 \%$ dos adotantes entrevistados eram do sexo feminino e $79,3 \%$ residia com o companheiro. Ambas as pesquisas refutam o paradigma de predomínio de adotantes solitários em busca de companhia.

A idade dos adotantes foi muito variável e as faixas etárias que se destacaram foram de 30 a 34 e 75 a 79 anos, com 18,8\% cada. No caso dos caninos destacou-se a faixa etária de 35 a 39 anos, com 30\% dos adotantes, e no caso de felinos destacou-se a faixa etária de 75 a 79 anos. Importante destacar que não houve adotantes com menos de 24 anos, entre 40 e 49 anos, 55 a 59 anos, 65 a 69 anos e maiores de 80 anos (Tabela 1). Os resultados se aproximam dos encontrados na pesquisa desenvolvida por Paploski et al. ${ }^{(26)}$ em que a idade média foi de 39 anos $( \pm 14,4)$. 
Tabela 1. Perfil socioeconômico dos adotantes de caninos e felinos no período 2011-2015 em Cachoeiras de Macacu-RJ

\section{Perfil socioeconômico dos adotantes}

\section{$\%$}

Canino Felino Total

\section{Estado Civil}

Solteiro

Casado/mora com companheiro

Separado/ divorciado

Sexo

Masculino

Feminino

Idade

$<20$ anos

$20-24$ anos

25 - 29 anos

$30-34$ anos

35 - 39 anos

40 - 44 anos

45 - 49 anos

50 - 54 anos

55 - 59 anos

$60-64$ anos

$65-69$ anos

$70-74$ anos

75 - 79 anos

80 ou mais anos

Nível de escolaridade (última completa)

Fundamental

Médio

Superior

Pós-Graduação

Renda familiar mensal bruta

1 - 2 salários mínimos

2 - 3 salários mínimos

3 - 5 salários mínimos

5 - 10 salários mínimos

$>10$ salários mínimos
$30 \quad 33,3 \quad 31,2$

$\begin{array}{lll}70 & 50 & 62,4\end{array}$

$\begin{array}{lll}0 & 16,7 & 6,3\end{array}$

$30 \quad 16,7 \quad 25$

$\begin{array}{lll}70 & 83,3 & 75\end{array}$

$\begin{array}{lll}0 & 0 & 0\end{array}$

$\begin{array}{lll}0 & 0 & 0\end{array}$

$\begin{array}{lll}10 & 0 & 6,2\end{array}$

$20 \quad 16,7 \quad 18,8$

$30 \quad 16,7 \quad 25$

$0 \quad 0 \quad 0$

$0 \quad 0 \quad 0$

$10 \quad 16,7 \quad 12,5$

$0 \quad 0 \quad 0$

$20 \quad 0 \quad 12,5$

$0 \quad 0 \quad 0$

$\begin{array}{lll}0 & 16,7 & 6,2\end{array}$

$10 \quad 33,3 \quad 18,8$

$0 \quad 0 \quad 0$

$10 \quad 0 \quad 6,2$

$30 \quad 50 \quad 37,6$

$50 \quad 50 \quad 50$

$10 \quad 0 \quad 6,2$

$30 \quad 16,7 \quad 4$

$\begin{array}{lll}0 & 16,7 & 1\end{array}$

$10 \quad 0 \quad 1$

$40 \quad 50 \quad 7$

$20 \quad 16,6 \quad 3$

Houve predomínio de adotantes com nível superior, seguido de nível médio e com renda alta (acima de cinco salários mínimos mensais) (Tabela 1). Esses resultados de renda não coadunam com os encontrados por Paploski et al. ${ }^{(26)}$, que encontraram renda média mensal menor entre os adotantes. Frank $^{(33)}$ encontrou associação da adoção de animais com menor renda e com menor escolaridade quando comparado com a compra de animais. Estudo de Domingues et al. ${ }^{(29)}$ mostrou que a guarda responsável melhora com o aumento da escolaridade e, segundo Reichmann et al. ${ }^{(3)}$ a densidade 
populacional de animais domésticos é mais baixa nas classes sociais mais abastadas, que são exatamente aquelas com melhores condições econômicas para manter esses animais.

Na maior parte dos imóveis onde houve adoção de animais não havia idosos residindo (66\%) e nem crianças (92\%). Em nenhum imóvel onde houve adoção de felinos havia criança residindo. Esses dados mostram que os animais, de modo geral, não foram adotados no intuito de socializar e fazer companhia especificamente a crianças e idosos. Azevedo et al. ${ }^{(24)}$ também constataram que somente $1,5 \%$ dos animais de companhia foram adquiridos para socializarem com crianças.

Houve predomínio de imóveis com quintal, terraço ou área externa (78\%), tanto para caninos (89,5\%) quanto para felinos (71\%) (Tabela 2). Os resultados coadunam com os encontrados por Canatto et al. ${ }^{(19)}$, nos quais houve forte predomínio de animais nas residências (mais de 96\%) e pouquíssimos em empresas (menos de 3\%).

Tabela 2. Perfil dos imóveis onde houve adoção de caninos e felinos no período 2011-2015 em Cachoeiras de Macacu-RJ

\begin{tabular}{|c|c|c|c|c|c|c|}
\hline \multirow[t]{2}{*}{ Perfil dos imóveis } & \multicolumn{2}{|c|}{ Canino } & \multicolumn{2}{|c|}{ Felino } & \multicolumn{2}{|c|}{ Total } \\
\hline & $\mathbf{N}^{0}$ & $\%$ & $\mathbf{N}^{\circ}$ & $\%$ & $\mathbf{N}^{\circ}$ & $\%$ \\
\hline \multicolumn{7}{|l|}{ Idosos residentes } \\
\hline $\operatorname{Sim}$ & 9 & 47,4 & 8 & 25,8 & 17 & 34 \\
\hline Não & 10 & 52,6 & 23 & 74,2 & 33 & 66 \\
\hline \multicolumn{7}{|l|}{ Crianças residentes } \\
\hline $\operatorname{Sim}$ & 4 & 21,1 & 0 & 0 & 4 & 8 \\
\hline Não & 15 & 78,9 & 31 & 100 & 46 & 92 \\
\hline \multicolumn{7}{|l|}{ Tipo de imóvel } \\
\hline Casa sem quintal, terraço ou área externa & 0 & 0 & 2 & 6,5 & 2 & 4 \\
\hline Casa com quintal, terraço ou área externa & 17 & 89,5 & 22 & 71 & 39 & 78 \\
\hline Sítio & 0 & 0 & 1 & 3,2 & 1 & 2 \\
\hline Empresa & 2 & 10,5 & 6 & 19,3 & 8 & 16 \\
\hline
\end{tabular}

No caso dos caninos, o principal motivo da adoção foi a pena do animal, em todos os níveis educacionais, exceto para os pós-graduados, onde foi a companhia. Já no caso dos felinos também predominou a pena do animal em todos os níveis educacionais. (Figuras 2 e 3). Diversas pesquisas vêm demonstrando predomínio da companhia e da segurança como motivações para se ter um animal de estimação ${ }^{(34,20,28,30)}$. Já diversos estudos vêm mostrando que o principal motivo para adoção de animais foi o fato dos adotantes gostarem de animais ${ }^{(8,19,24)}$. De modo geral, a afeição pelos animais, seja pelo fato de gostar deles e ter pena, seja pelo fato de querê-los como companhia são fatores que preponderam na opção por ter um animal de estimação.

A semelhança com alguma raça só foi importante para um adotante de canino. Esse dado coaduna com os encontrados por Paploski et al. ${ }^{(26)}$, que constatou que $72,4 \%$ dos adotantes buscavam animais sem raça definida. Wiess et al. ${ }^{(23)}$ também encontrara associação entre adoção e animais sem raça definida. Apesar disso, estudo desenvolvido por Posage et al. ${ }^{(25)}$ demonstrou o animal ser de raça era um fator importante na opção pela adoção do animal em abrigo nos EUA. 


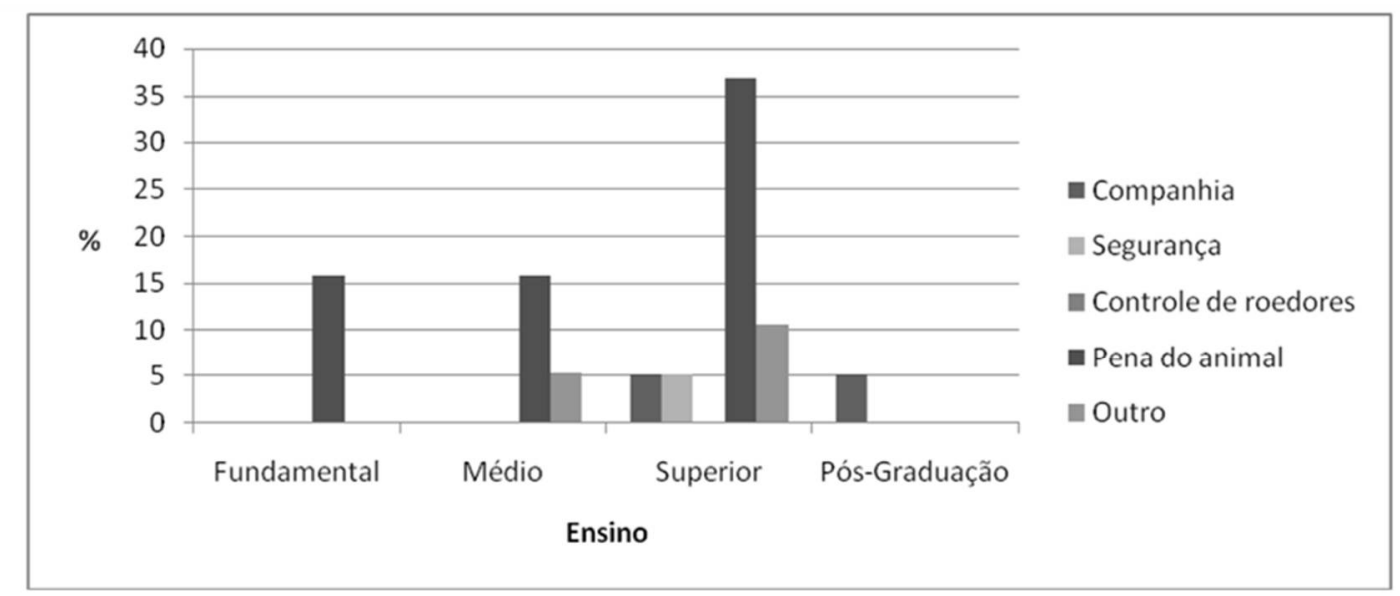

Figura 2. Motivo de adoção de caninos no período 2011-2015, por nível educacional em Cachoeiras de Macacu-RJ

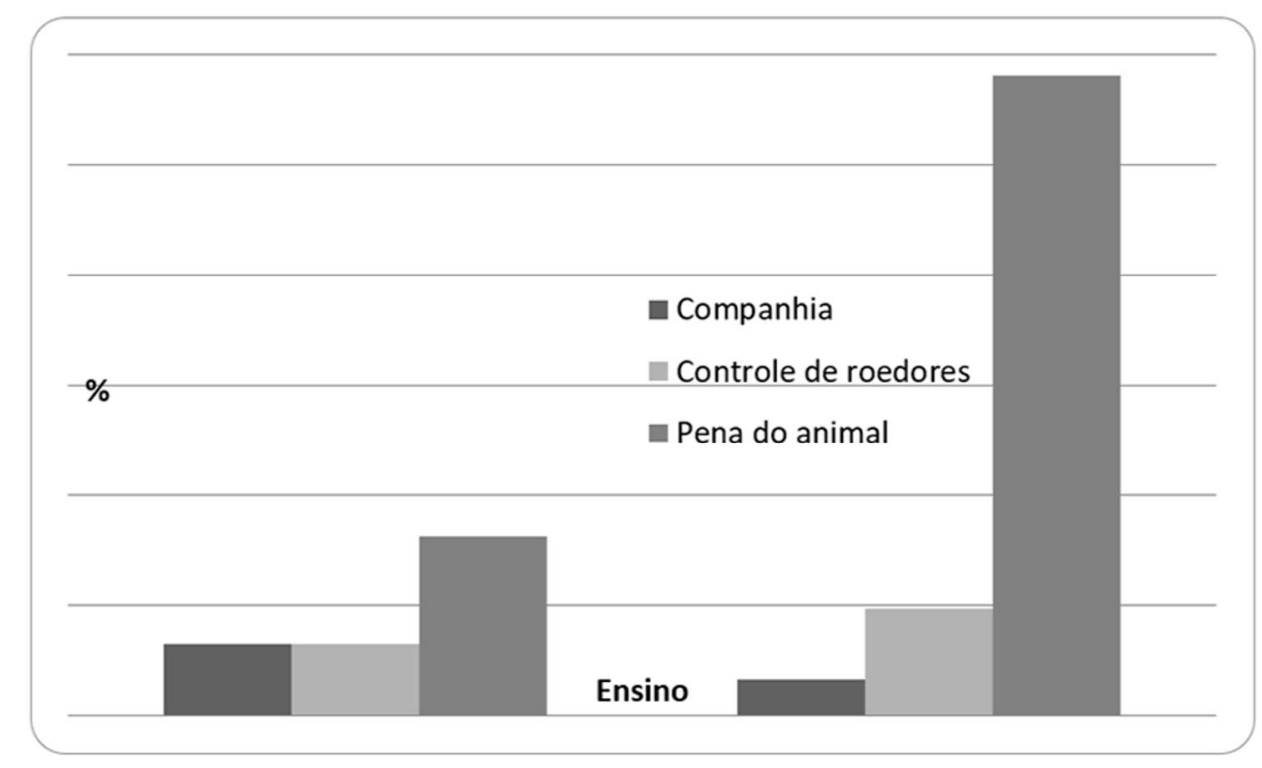

Figura 3. Motivo de adoção de felinos no período 2011-2015, por nível educacional em Cachoeiras de Macacu-RJ.

Em 93,5 \% (n=29) dos casos em que houve adoção de felinos o adotante já dispunha de animal em casa, sendo em $72,4 \%(n=21)$ canino e felino, em 17,2\% $(n=5)$ felino e em 10,4\% $(n=3)$ canino. Em $94,8 \%(\mathrm{n}=18)$ dos casos em que houve adoção de canino o adotante já dispunha de animal em casa, sendo $50 \%(\mathrm{n}=9)$ caninos e felinos e $50 \%(\mathrm{n}=9)$ caninos. Os resultados mostram predomínio evidente da opção por mais um animal entre os adotantes. Ainda que numa proporção expressivamente maior, esses resultados estão de acordo com aqueles encontrados por Paploski et al. ${ }^{(26)}$, em que 58,6\% dos adotantes já dispunham de outro animal em casa.

No que diz respeito ao local onde o animal ficava a maior parte do tempo, $48 \%(n=24)$ ficavam tanto no interior do imóvel como no quintal terraço ou área externa. No caso dos caninos havia forte predomínio de animais que ficavam fora de casa $(63,1 \% / \mathrm{n}=12)$ e no caso dos felinos havia predominância de animais que ficavam nos ambientes interno e externo $(67,8 \% / n=21)$ (Tabela 3 ). 
Tabela 3. Manejo de caninos e felinos adotados no periodo 2011-2015 em Cachoeiras de Macacu-RJ

\begin{tabular}{|c|c|c|c|c|c|c|}
\hline \multirow[t]{2}{*}{ Manejo do animal adotado } & \multicolumn{2}{|c|}{ Canino } & \multicolumn{2}{|c|}{ Felino } & \multicolumn{2}{|c|}{ Total } \\
\hline & $\mathrm{N}^{\circ}$ & $\%$ & $\mathrm{~N}^{\circ}$ & $\%$ & $\mathrm{~N}^{\circ}$ & $\%$ \\
\hline \multicolumn{7}{|c|}{ Local onde passa a maior parte do tempo } \\
\hline Quintal, terraço ou área externa & 12 & 63,1 & 2 & 6,4 & 14 & 28 \\
\hline Interior do imóvel & 4 & 21,1 & 5 & 16,1 & 9 & 18 \\
\hline Ambos & 3 & 15,8 & 21 & 67,8 & 24 & 48 \\
\hline Outro & 0 & 0 & 3 & 9,7 & 3 & 6 \\
\hline \multicolumn{7}{|l|}{ Acesso à rua } \\
\hline Sozinho & 1 & 5,2 & 18 & 58,1 & 19 & 38 \\
\hline Acompanhado & 4 & 21,1 & 1 & 3,2 & 5 & 10 \\
\hline Não tem & 14 & 73,7 & 12 & 38,7 & 26 & 52 \\
\hline \multicolumn{7}{|l|}{ Alimentação } \\
\hline Ração exclusivamente & 18 & 94,8 & 31 & 100 & 49 & 98 \\
\hline Comida de panela exclusivamente & 1 & 5,2 & 0 & 0 & 1 & 0 \\
\hline Ração e comida de panela & 0 & 0 & 0 & 0 & 0 & 0 \\
\hline \multicolumn{7}{|l|}{ Vacinação* } \\
\hline Somente contra Raiva & 0 & 0 & 4 & 13,8 & 4 & 8,3 \\
\hline Somente Múltipla & 1 & 5,2 & 1 & 3,4 & 2 & 4,2 \\
\hline Ambas & 18 & 94,8 & 24 & 82,8 & 42 & 87,5 \\
\hline \multicolumn{7}{|l|}{ Local da vacinação contra Raiva* } \\
\hline Campanha pública & 8 & 42,2 & 2 & 6,9 & 10 & 20,8 \\
\hline Veterinário particular & 11 & 57,8 & 27 & 93,1 & 38 & 79,2 \\
\hline \multicolumn{7}{|l|}{ Periodicidade da desverminação } \\
\hline Semestral & 13 & 68,5 & 28 & 90,3 & 41 & 82 \\
\hline Anual & 1 & 5,2 & 3 & 9,7 & 4 & 8 \\
\hline Quanto visualiza verme & 3 & 15,8 & 0 & 0 & 3 & 6 \\
\hline Não sabe & 2 & 10,5 & 0 & 0 & 2 & 4 \\
\hline \multicolumn{7}{|c|}{ Periodicidade de consulta veterinária } \\
\hline Nunca & 1 & 5,3 & 2 & 6,4 & 3 & 6 \\
\hline Em emergência & 12 & 63,1 & 13 & 42 & 25 & 50 \\
\hline Semestral & 4 & 21,1 & 15 & 48,4 & 19 & 38 \\
\hline Tutor é veterinário & 2 & 10,5 & 1 & 3,2 & 3 & 6 \\
\hline \multicolumn{7}{|l|}{ Dispositivo de identificação } \\
\hline Plaquinha & 3 & 15,8 & 0 & 0 & 3 & 6 \\
\hline Tatuagem & 0 & 0 & 0 & 0 & 0 & 0 \\
\hline Chip & 0 & 0 & 0 & 0 & 0 & 0 \\
\hline Nenhum & 16 & 84,2 & 31 & 100 & 47 & 94 \\
\hline
\end{tabular}

* Três gatos ainda não tinham idade apropriada para vacinação.

Apesar da maior parte $(52 \% / \mathrm{n}=26)$ ter relatado que os animais adotados não tinham acesso à rua sozinhos, um percentual relevante de 38\% $(\mathrm{n}=19)$ tinha esse acesso. No caso dos caninos, 73,7\% $(n=14)$ não tinham acesso sozinhos à rua, mas no caso dos felinos $58,1 \%(n=18)$ o tinham (Tabela 3$)$. 
Alves et al. (21) demonstram que a situação de restrição territorial dos animais é proporcional ao tamanho das cidades, sendo menor nas cidades de menor porte, como é o caso do município onde a pesquisa foi desenvolvida. Pesquisa desenvolvida por Silvano et al. ${ }^{(22)}$ detectou que a maioria dos animais tinham livre acesso à rua desacompanhados. Canatto et al. ${ }^{(19)}$ demonstraram que $64,4 \%$ dos cães tinham livre acesso à rua, contra $42,5 \%$ dos gatos. Outro estudo demonstrou que 19,5\% dos animais tinham livre acesso à rua e $26,9 \%$ dos gatos eram criados totalmente soltos, com total acesso à rua. De Carli \& Morais ${ }^{(28)}$ encontraram 9,2\% dos cães e $50 \%$ dos gatos com livre acesso à rua. Catapan et al. ${ }^{(20)}$ encontraram $6,3 \%$ dos cães e $36 \%$ dos gatos com livre acesso à rua. Percebe-se que a restrição territorial de felinos é mais negligenciada do que a de caninos, o que é um grande risco para a transmissão de zoonoses, especialmente a esporotricose, que vem se apresentando como uma importante epidemia zoonótica associada aos gatos no estado do Rio de Janeiro ${ }^{(35,36)}$.

No que diz respeito à alimentação, 98\% $(n=49)$ dos animais eram alimentados somente com ração comercial e apenas um canino era alimentado com comida de panela (preparada em casa) (Tabela 3). Diversos estudos vêm demonstrando o predomínio da alimentação industrializada dos animais domésticos $^{(15,27,28)}$. Mas, estudo conduzido por Azevedo et al.(24) demonstrou predomínio da alimentação caseira em detrimento da industrializada. Além do fato das rações comerciais apresentarem formulação balanceada e apropriada aos animais ${ }^{(3)}$, seu uso facilita o dia a dia dos proprietários de animais, tendo em vista a praticidade.

A vacinação contra raiva e com a vacina múltipla era realizada em $87,5 \%(n=42)$ dos animais em idade apropriada. O mesmo acontecia com caninos $(94,8 \% / n=18)$ e felinos $(82,8 \% / n=24)$ (Tabela 3). Apesar da obrigatoriedade da vacinação antirrábica de animais domésticos no estado do Rio de Janeiro $^{(4)}$ e da recomendação para que os cães sejam vacinados, além da raiva, com a vacina múltipla, minimamente contra hepatite canina, parvovirose, coronavirose e leptospirose ${ }^{(3)}$, os resultados encontrados se opõem fortemente aos encontrados em outros estudos, que apresentaram percentuais bem mais baixos de vacinação( ${ }^{(27,29)}$. Os resultados encontrados se aproximam mais daqueles encontrados por Langoni et al. ${ }^{(15)}$, sobre a vacinação contra raiva, os quais $97,1 \%$ vacinavam contra raiva, apesar de somente $46,9 \%$ fazerem a vacinação múltipla, Carvalho et al. ${ }^{(14)}$ em que $80 \%$ dos cães e $93 \%$ dos gatos recebiam a vacina antirrábica, Cardoso et al. ${ }^{(30)}$ em que $91,2 \%$ vacinavam contra raiva e $49,1 \%$ desses também com a múltipla, De Carli \& Novais ${ }^{(28)}$, que encontraram 91,7\% dos gatos vacinados contra raiva, contra somente $53,8 \%$ dos cães, e Catapan et al. ${ }^{(20)}$ em que $84,8 \%$ dos cães e $70,8 \%$ dos gatos vacinados com a antirrábica e a múltipla.

A maioria dos animais $(79,2 \% / n=38)$ era vacinada em estabelecimentos privados, sendo $57,8 \%$ $(n=11)$ em caninos e 93,1\% $(n=27)$ em felinos (Tabela 3). Esses resultados diferem daqueles encontrados por Langoni et al. ${ }^{(15)}$, os quais $100 \%$ dos animais eram vacinados contra raiva em campanhas públicas e por De Carli \& Novais ${ }^{(28)}$, que encontraram $60 \%$ dos cães e $100 \%$ dos gatos vacinados contra raiva na campanha pública. Também, Carvalho et al. ${ }^{(14)}$ encontraram predomínio de vacinação na campanha pública, com $67 \%$ dos cães e $73 \%$ dos gatos.

A desverminação periódica era realizada em $82 \%(n=41)$ dos animais adotados, sendo em 90,3\% $(n=28)$ dos felinos e 68,5\% $(n=13)$ dos caninos (Tabela 3). Apesar da desverminação periódica ser recomendada desde a mais tenra idade ${ }^{(3)}$, diversos estudos vêm demonstrando, ao contrário do encontrado no presente estudo, baixos índices de desverminação periódica nos animais domésticos $^{(27,24,30)}$. Somente Domingues et al. ${ }^{(29)}$ e Catapan et al. ${ }^{(20)}$ encontraram resultados mais próximos, com $72 \%$ e $84 \%$ dos animais desverminados, respectivamente. Estudo desenvolvido por Brener et al. ${ }^{(37)}$ mostrou a viabilidade da transmissão de helmintoses zoonóticas em praças públicas do Estado do Rio de Janeiro em função da contaminação destas por ovos e larvas oriundos das fezes de animais. 
Metade dos animais adotados $(\mathrm{n}=25)$ só eram levados ao veterinário em emergências. No caso de caninos, isso ocorria em $63,1 \%(n=12)$, mas no caso dos felinos 48,4\% $(n=15)$ dos animais eram levados semestralmente para consulta veterinária (Tabela 3). Diversos estudos vêm demonstrando baixa adesão ao acompanhamento veterinário e que os animais somente são levados para consulta veterinária em casos emergenciais ou nunca são levados ao veterinário ${ }^{(34,22,14,15,24,28,30)}$. Somente Catapan et al. ${ }^{(20)}$ encontraram resultados melhores que os da presente pesquisa, com $54,6 \%$ tendo acompanhamento veterinário periódico.

Considerando o quadro preocupante no que tange ao acompanhamento médico sanitários dos animais, é importante salientar que quando uma pessoa opta por adquirir um animal doméstico, ela deve assumir a responsabilidade pela sua saúde e seu bem-estar enquanto o animal com ela permanecer ${ }^{(18)}$.

$\mathrm{Na}$ amostra pesquisada, 94\% $(\mathrm{n}=47)$ dos animais não apresentavam nenhum tipo de dispositivo de identificação, sendo que essa identificação só ocorria em 15,8\% $(n=3)$ dos caninos, com uso de plaquinha (Tabela 3). Recomenda-se, apesar de não ser uma prática comum no Brasil, que os animais domésticos sejam dotados de um dispositivo de identificação, preferencialmente permanente, como tatuagem ou microchip ${ }^{(18)}$. A adoção de métodos permanentes de identificação auxilia no combate ao abandono já que há rastreabilidade do tutor e, assim, possibilidade de aplicar as sanções previstas na legislação( ${ }^{(38)}$.

Dos 50 animais adotados, 46 (92\%) permaneciam com o adotante no momento da entrevista, num período que variou de dois meses a três anos após a adoção. Nenhum animal havia sido devolvido para a ONG. Dos 31 felinos adotados, 87,1\% $(\mathrm{n}=27)$ permaneciam com o adotante, 9,7\% $(\mathrm{n}=3)$ haviam fugido e 3,2\%(n=1) havia morrido. Já em relação aos caninos, $100 \%(n=19)$ permaneciam com o adotante. Em pesquisa realizada com adotantes de animais, Soto et al. ${ }^{(8)}$ identificaram que $65,7 \%$ dos animais ainda permaneciam com os adotantes, $15,7 \%$ morreram, $10,5 \%$ foram doados para terceiros e 7,8\% haviam fugido. Ainda que segundo indicadores indiretos, Frank ${ }^{(33)}$ detectou um vínculo maior do proprietário com o animal quando esse é adotado.

Em relação a possíveis dificuldades do adotante em relação ao animal adotado, 70\% ( $\mathrm{n}=35$ ) informaram não terem tido dificuldades. Dos 31 felinos adotados, 74,2\% ( $n=23)$ dos adotantes informaram não terem tido dificuldades com o animal adotado. Dos $25,8 \%(n=8)$ que informaram terem tido dificuldades, $25 \%(\mathrm{n}=2)$ alegaram o temperamento difícil, $37,5 \%(\mathrm{n}=3)$ ferocidade, $25 \%$ $(n=2)$ enfermidade e 12,5\% $(n=1)$ outro motivo. Dos 19 caninos adotados, $63,2 \%(n=12)$ dos adotantes informaram não terem tido dificuldades com o animal adotado. Dos $36,8 \%$ ( $n=7$ ) que informaram terem tido dificuldades, 42,8\% $(n=3)$ alegaram enfermidade, 28,6\% $(n=2)$ temperamento difícil, $14,3 \%(n=1)$ comportamento de fuga e 14,3\% $(n=1)$ excesso de latidos. Em pesquisa realizada com adotantes de animais Soto et al. ${ }^{(8)}$ identificaram que a doença foi a maior dificuldade enfrentada pelos adotantes. Já Alves et al. ${ }^{(39)}$ listam como as principais possíveis causas de abandono dos animais os problemas comportamentais, a falta de espaço, o estilo de vida dos proprietários, a falta de informação sobre as responsabilidades em relação à guarda de um animal e os custos envolvidos. Os problemas que levam à devolução de animais adotados muitas vezes são difíceis de serem identificados no momento da adoção, como a interação com outros animais ou crianças, por exemplo. Outras vezes estão relacionados com a falta de preparo ou informação dos adotantes, envolvendo o tamanho do animal quando crescido e a falta de tempo para dedicar ao animal ${ }^{(40,41)}$. Por isso é fundamental que, no momento da aquisição de um animal de estimação, o adquirente receba informações relevantes em relação aos custos, ao comportamento normal dos animais, as vantagens da castração, as consequências do abandono, etc. ${ }^{(38)}$. Em relação ao nível de satisfação dos adotantes com os animais adotados, 96\% $(n=48)$ demonstraram estar muito satisfeitos e $4 \% \quad(n=2)$ demonstraram estar satisfeitos. Nenhum adotante afirmou estar totalmente insatisfeito ou indiferente 
em relação à adoção. No caso dos caninos, $100 \%(\mathrm{n}=19)$ estavam muito satisfeitos e no caso dos felinos, 93,5\% $(n=29)$ demonstraram estar muito satisfeitos, enquanto 6,5\% $(n=2)$ demonstraram estar satisfeitos com a adoção. Esses resultados são animadores e bem próximos dos encontrados por Soto et al. ${ }^{(8)}$, que mostraram que a adaptação dos novos proprietários aos animais adotados em Ibiúna (SP) era boa ou ótima para $96,1 \%$ dos adotantes.

\section{Conclusões}

A adoção de animais é uma das estratégias utilizadas para diminuir a densidade populacional de animais não domiciliados. A semelhança com alguma raça não foi um critério utilizado pela maioria dos adotantes e, inclusive, houve adoção de animais portadores de necessidades especiais. Foram adotados principalmente animais mais jovens e o perfil dos adotantes era de indivíduos casados, do sexo feminino, de idade variável, envolvendo de adultos jovens a idosos, com escolaridade em nível superior e renda alta. De modo geral, as adoções não se deram em função da interação dos animais com idosos e crianças, os adotantes já dispunham de outro animal e os animais adotados passaram a residir principalmente em imóveis residenciais, com quintal, terraço ou área externa. A maior parte dos animais tinha acesso às áreas interna e externa desses imóveis. No que tange à motivação da adoção predominou o sentimento de pena em relação aos animais.

Importante notar que o estudo demonstrou que os princípios de guarda responsável estavam sendo parcialmente seguidos, o que pode ser comprovado pela proporção de animais castrados encontrados, predomínio de alimentação com ração balanceada, boa cobertura vacinal contra a raiva e com a vacina múltipla e predomínio de animais que recebiam desverminação periódica.

Ainda assim, foram encontradas situações que desviam da guarda responsável, como o predomínio de animais com acesso livre às ruas, predomínio da deficiência no acompanhamento veterinário preventivo e ausência de dispositivo de identificação permanente.

De modo geral, houve grande vínculo dos adotantes com os animais, o que pode ser comprovado pelo alto índice de permanência dos adotantes com os animais, pela baixa proporção de dificuldades na lida com os animais e pelo alto grau de satisfação dos adotantes em relação aos animais.

O quadro encontrado no presente estudo, ainda que não deva ser extrapolado para outras populações de animais adotados, por se tratar de uma amostra selecionada por conveniência em apenas um município do estado do Rio de Janeiro, é consideravelmente animador e demonstra que a estratégia da adoção foi eficiente e pode trazer bons resultados no controle da densidade populacional de animais não domiciliados.

Por fim, é fundamental salientar que o enfrentamento de tal problema deve envolver diferentes estratégias simultaneamente, já que nenhuma estratégia isolada trará resultados satisfatórios, pois se trata de problema com causa multifatorial.

\section{Referências}

1. Silva MHS, Silva JA, Magalhães DF, Silva MX, Meneses JNC, Moreira EC. Caracterização demográfica e epidemiológica de cães e gatos domiciliados em Barbacena, MG. Arquivos Brasileiros de Medicina Veterinária e Zootecnia. 2010;62(4):1001-1006. 
2. Vieira AML, Almeida AB, MagnaboscoC,Ferreira JCP, Luna SLP, Carvalho JLB, Gomes LH, Paranhos NT, Reichmann ML, Garcia RC, Nunes VFP, Cabral VB. Programa de controle de cães e gatos do Estado de São Paulo. BEPA [periódico na Internet]. 2006;3(25). [cited 2012 Fev 22]. Disponível em http://www.cve.saude.sp.gov.br/agencia/bepa25_rg7caes.htm.

3.Reichmann MLAB, Figueiredo ACC, Pinto HBF, Nunes VFP. Controle de populações de animais de estimação. São Paulo: Instituo Pasteur, 2000. 2009 [cited 2014 Jun 05]. Disponível em http://www.saude.sp.gov.br/resources/instituto-pasteur/pdf/manuais/manual_06.pdf.

4. Rio de Janeiro. Lei n ${ }^{\circ} 4.808$ de 04 de julho de 2006. Dispõe sobre a criação, a propriedade, a posse, a guarda, o uso, o transporte e a presença temporária ou permanente de cães e gatos no âmbito do estado do Rio de
Janeiro.
[cited
2010
Jul
24].
Disponível

em http://alerjln1.alerj.rj.gov.br/contLei.nsf/c8aa0900025feef6032564ec0060dfff/

6628191723549496832571a8005e8896?opendocument.

5. Bortoloti R; D’agostino RG. Ações pelo controle reprodutivo e posse responsável de animais domésticos interpretadas à luz do conceito de metacontingência. Revista brasileira de análise do comportamento. 2007;3(1):17-28.

6. Dilly BLG; Costa Júnior NB; Freitas RB; Frasceschini EM. Tratamento dado ao problema de abandono de cães na UNICAMP. Revista Ciências do Ambiente On-line, v. 5, n. 1, ago, 2005. Disponível em http://sistemas.ib.unicamp.br/be310/viewarticle.php?id=27. Acesso: 13 de outubro de 2009.

7. Gomes NSC. Uma perspectiva da construção dos direitos da fauna doméstica do município de Belo Horizonte - MG. Revista Brasileira de Direito Animal. 2010; 5(7):285-305.

8. Soto FRM; de Souza AJ, Risseto MR; Lima BFMS. Adoção de cães no município de Ibiúna - SP - Brasil: análise crítica. Revista Ciência em Extensão. 2006;3(1):26.

9. Soares, P. O papel da informação em entidades de proteção animal. Estudo de caso: Instituto Nina Rosa. Trabalho de Conclusão de Curso (Bacharelado em Biblioteconomia e Documentação). Escola de Comunicações e Artes. São Paulo: USP, 2006. 93 p.

10. Moutinho FFB; Nascimento ER; Paixão RL. Percepção da sociedade sobre a qualidade de vida e o controle populacional de cães não domiciliados. Revista Ciência Animal Brasileira. 2015;16(4):574-588.

11. Castro MS. A evolução dos direitos animais em Florianópolis. Revista Santa Catarina em História. 2011;5(2):103-116.

12. Lui JF, Toniollo GH, Savi PAP, Voorwald FA, Silva MAM, Tosta PA. Esterilização cirúrgica de caninos e felinos em Jaboticabal. Interação entre o benefício social e a pesquisa científica. Revista Ciência em Extensão. 2011;7(2):33.

13. Souza MFA. Controle de populações caninas: considerações técnicas e éticas. Revista Brasileira de Direito Animal. 2011;8(6):115-133.

14. Carvalho AAB, Grisólio APR, Bueno GM, Testi AJP, Martins MC, Portela LC, Servidone JS, Nunes JOR. Caracterização da população de cães e gatos e avaliação do nível de conhecimento dos moradores sobre zoonoses e posse responsável de animais de estimação em bairros do município de Jaboticabal / SP. Revista Ciência em Extensão. 2011;7(2):158-159.

15. Langoni H, Troncarelli MZ, Rodrigues EC, Nunes HRC, Harumi V, Henriques MV, Silva KM, Shimono JY. Conhecimento da população de Botucatu - SP sobre Guarda Responsável de cães e gatos. Veterinária e Zootecnia. 2011;18(2):297-305.

16. Netto LC; de Faria Lima F; Perri SHV; de Koivisto MB; Bresciani KDS. Programa de conscientização de idosos sobre posse responsável de animais de estimação em bairro periférico do município de Araçatuba, SP. Revista Ciência em Extensão. 2011;7(2):102-109. 
17. Garcia RCM, Maldonado NAC, Lombardi A. Controle populacional de cães e gatos. Ciências veterinárias nos trópicos; 2008;11(1):106-110.

18. Organização Internacional de Saúde Animal - OIE. Control de laspoblaciones de perros vagabundos. In: OIE. Código Sanitario para losAnimales Terrestres - 2016. 2016 [cited 2016 Set 27]. Disponível em: http://www.oie.int/es/normas-internacionales/codigo-terrestre/acceso-en-linea/.

19. Canatto BD, Silva EA, Bernardi F, Mendes MCNC, Paranhos NT, Dias RA. Caracterização demográfica das populações de cães e gatos supervisionados do município de São Paulo. Arquivos Brasileiros Medicina Veterinária e Zootecnia. 2012;64(6):1515-1523.

20. Catapan DC; Junior JAV; Weber SH; Mangrich RMV; Szczypkovski AD; Catapan A; Pimpão CT. Percepção e atitudes do ser humano sobre guarda responsável, zoonoses, controle populacional e cães em vias públicas. Revista Brasileira de Ciência Veterinária. 2015;22(2)92-98.

21. Alves MCGP, Matos MR, Reichmann ML, Dominguéz MH. Dimensionamento da população de cães e gatos do interior do Estado de São Paulo. Revista de Saúde Pública. 2005; 39(6):891-897.

22. Silvano D, Bendas AJR, Miranda MGN, Pinhão R, Mendes de Almeida F, Labarthe NV, Paiva JP. Divulgação dos princípios de guarda responsável: uma vertente possível no trabalho de pesquisa a campo. Revista Eletrônica Novo Enfoque. 2010;9(9):64-86.

23. Weiss E; Miller K; Mohan-Gibbons H; Vela C. Why Did You Choose This Pet?: Adopters and Pet Selection Preferences in Five Animal Shelters in the United States.Animals. 2012;2(2):144-159.

24. Azevedo CF; Costa Neto BM; Bezerra AC; Lima Júnior AR. Avaliação do bem estar de animais de companhia na comunidade da vila florestal em lagoa seca/PB. Archives of Veterinary Science. 2015;20(2):0615.

25. Posage, JM; Bartlett PC; Thomas DK..Determining factors for successful adoption of dogs from an animal shelter.J. Am. Vet. Med. Assoc. 1998;213(4):478-482.

26. Paploski IAD, Babboni SD, González GK, Giarola RM, Rodrigues SA, Cerqueira ATAR, Padovani CR, Victória C, Modolo JR. Características dos adotantes de cães na área urbana de Botucatu. Veterinária e Zootecnia. 2012;19(4):584-592.

27. Loss LD; Mussi JMS; Mello INK;Leão MS;Franque MP. Posse responsável e conduta de proprietários de cães no município de Alegre-ES. Acta VeterinariaBrasilica. 2012;6(2):105-111.

28. De Carli CB; Novais AA. Guarda responsável de cães e gatos do Município de Sinop / MT: estudo descritivo. Sci. Elec. Arch. 2015;8(1):26-30.

29. Domingues LR; Cesar JÁ; Fassa AG; Domingues MR.Guarda responsável de animais de estimação na área urbana do município de Pelotas, RS, Brasil. Ciência \& Saúde Coletiva. 2015;20(1):185-192.

30. Cardoso DP; Oliveira RP; Sousa Estrela D; Saraiva LA; Farias MPO; Silva PO. Perfil dos tutores de cão e gato no município de Bom Jesus - PI. Pubvet. 2016;10(8):580-586.

31. Patronek GJ; Beck AM; Glickman LT. Dynamics of dog and cat populations in a community. J. Am. Vet. Med. Assoc. 1997;210(5):637-642.

32.Amaku M; Dias RA; Ferreira F. Dinâmica populacional canina: potenciais efeitos de campanhas de esterilização. Rev Panam Salud Publica. 2009;25(4):300-4.

33. Frank AC. Semelhanças e diferenças entre adotar, comprar ou ganhar um cão de companhia na cidade de São Paulo. Dissertação (Mestrado em Ciências) - Faculdade de Medicina Veterinária e Zootecnia, Universidade de São Paulo, São Paulo, 2015, 106 p. Disponível em: http://www.teses.usp.br/teses/disponiveis/10/10134/tde-28012016143527/publico/ALICE_DE_CARVALHO_FRANK_Corrigida.pdf 
34. Silva FAN; Carvalho RL; Klein RP; Quessada AM. Posse responsável de cães no bairro Buenos Aires na cidade de Teresina (PI). ARS Veterinária. 2009;25(1):14-17.

35. Barros MBDL; Schubach TP; Coll JO; Gremião ID; Wanke B; Schubach A.Esporotricose: a evolução e os desafios de uma epidemia. Rev Panam Salud Publica. 2010;27(6):4554-60.

36. Silva MBTD; Costa MMDM; Torres CCDS; Galhardo MCG; Valle ACFD; Magalhães MDAF; Sabroza PC; Oliveira RMD.Esporotricose urbana:epidemia negligenciada no Rio de Janeiro, Brasil. Cadernos de Saúde Pública. 2012;28(10):1867-1880.

37. Brener B; Mattos DPBG; Millar PR; Arashiro EKN; Duque-Ferreira V; Sudré AP. Estudo da contaminaçãode praças públicas de três municípiosdo estado do Rio de Janeiro, Brasil,por ovos e larvas de helmintos. Revista de Patologia Tropical. 2008;37(3):247-254.

38. D'ANDRETTA, J. P. M. Análise de fatores que contribuíram para a guarda responsável ou abandono de cães e gatos em área de São Paulo / SP. Dissertação (Mestrado) - Universidade de Saõ Paulo. Faculdade de Veterinária e Zootecnia, São Paulo, 2012, 107 p. Disponível em: http://www.teses.usp.br/teses/disponiveis/10/10134/tde-24042013141324/publico/JOAO PAULO MARQUES D ANDRETTA Corrigida.pdf

39. Alves AJS; Guilloux AGA; Zetun CB; Polo G; Braga GB;Panachão LI; Santos O; Dias RA. Abandono de cães na America Latina: revisão de literatura. Revista de Educação Continuada em Medicina Veterinária e Zootecnia do CRMV. 2013;11(2):34-41.

40. Mondelli F; Prato Previde E; Verga M; Levi D; Magistrelli S; Valsecchi P. The bond that never developed: adoption and relinquishment of dogs in a rescue shelter. J Appl AnimWelf Sci. 2004;7(4):253-66.

41. Shore ER. Returning a recently adopted companion animal: adopters' reasons for and reactions to the failed adoption experience. J Appl AnimWelf Sci. 2005;8(3):187-98. 